Article

\title{
Overall Performance Evaluation of Small Scale LNG Production Processes
}

\author{
Maria Alessandra Ancona *(1), Michele Bianchi ${ }^{-}$, Lisa Branchini, Francesco Catena, \\ Andrea De Pascale ${ }^{\circledR}$, Francesco Melino, Saverio Ottaviano $₫$ and Antonio Peretto
}

Alma Mater Studiorum, University of Bologna-DIN, Viale del Risorgimento 2, 40136 Bologna, Italy; michele.bianchi@unibo.it (M.B.); lisa.branchini2@unibo.it (L.B.); francesco.catena2@unibo.it (F.C.); andrea.depascale@unibo.it (A.D.P.); francesco.melino@unibo.it (F.M.); saverio.ottaviano2@unibo.it (S.O.); antonio.peretto@unibo.it (A.P.)

* Correspondence: maria.ancona2@unibo.it

Received: 28 November 2019; Accepted: 19 January 2020; Published: 22 January 2020

\begin{abstract}
The liquefied natural gas (LNG) is considered a viable solution to replace oil-based engines (common in heavy-duty truck and naval industry) reducing the environmental impact in the transport sector. Since liquefaction plants represent energy intensive processes, the best configurations/operation assessment is of primary importance. In this paper, a novel general procedure for the thermodynamic design and optimization, engineering design and off-design evaluation for small-scale LNG production systems is presented. The procedure can be used for the complete design and performance evaluation of plug \& play facilities at filling stations for vehicles/boats, with the contemporary benefits of reducing pollutant emission in the city/port area and operating as electrical storage, coupled with renewable generators. Furthermore, the procedure has been applied to a case study (ferry boat operating at the main canal in the port of Ravenna, Italy), evaluating the optimal size for the integrated wind plant by minimizing the electricity introduction into the grid. The obtained results show $78 \mathrm{~kW}$ as optimal wind size, allowing the LNG plant to operate $187 \mathrm{~h} /$ year in design and $4720 \mathrm{~h} /$ year in off-design conditions, with electricity surplus around $33 \mathrm{MWh} /$ year. A prototype will be installed to reduce pollutant emissions and test this technology as a storage option for renewable sources.
\end{abstract}

Keywords: LNG; transport sector; thermodynamic analysis; off-design calculation model; power to Liquid; small-scale application

\section{Introduction}

It is well known that in decades to come, natural gas (NG) is expected to cover an increasing portion of the supply demand in all the energy fields. Among all fossil fuels, it is the one with the best combination of natural reserves and acceptable emissions levels [1]. Focusing on the transport sector, at present, the fossil fuels utilization is responsible of about $26 \%$ of the total greenhouse gases emissions in the European Union, with the largest impact determined by road transport (72.9\%), followed by aviation (13.3\%) and the naval sector (12.8\%) [2]. The naval industry is also responsible for local air pollution, since it causes consistent concentration of $\mathrm{NO}_{\mathrm{x}}, \mathrm{SO}_{2}$ and $\mathrm{PM}$ in port areas [3]. These emissions have risen substantially since the 1970s with the growth of international trade [4]. Ships' propulsion systems are currently based on internal combustion engines fueled with diesel fuel or MDO (Marine Diesel Oil), the latter being often adopted due to its lower price compared to more refined fuels, despite the consistent content of sulfur [5]. The EU recently set stringent limitations on fuels for ships: starting from 2020, in the naval sector, the current fuels must be replaced with products with a maximum concentration of sulfur equal to $0.5 \%$ (at present it is equal to $3.5 \%$ ) [6]. In this context, the conversion of oil engines for working with liquefied natural gas (LNG) can become a convenient 
solution, as it has been assessed in several studies [7,8], observing a substantial benefit in terms of fuel cost and quantity of produced emissions. Compared to diesel, the adoption of LNG leads to an emission reduction of nearly $99 \%$ of particle and sulfur dioxide, around $80 \%$ of nitrogen oxides and close to $20 \%$ of carbon dioxide [7,8]. In [9], the authors investigated the possible solutions for the replacement of oil-based fuel within 2050 in naval sector, finding that the conversion to LNG fuel may be already cost effective, while other technologies like fuel cells and bioenergy could be convenient after 2040 and only if the NG supply becomes limited. Livanos et al. [10] performed a comparison of internal combustion engines as a propulsion system in a ferry or Ro-Ro ship, considering a dual fuel engine (LNG + diesel) versus a conventional diesel engine, including waste heat recovery systems for covering the electricity demand of the ship. They observed a reduction in annual costs due to the higher overall efficiency and to the lower price of LNG compared to diesel, in addition to a substantial reduction of emissions.

Currently, the production of LNG is realized almost exclusively in large scale plants (i.e., with capacity greater than 5 mega tons per annum-MTPA), via three main technologies: cascade process [11,12], mixed refrigerant process $[13,14]$ and expansion process $[15,16]$. The latter is seldom implemented with an expander instead of the Joule-Thomson valve for recovering useful power to reduce the process energy demand [17] involving a set of operations including transportation, storage and distribution, whose cost has a significant impact on the entire cost of the LNG value chain [18].

Relating to the small-scale LNG production plants, the most used configurations consist in single mixed refrigerant liquefaction process and nitrogen expansion liquefaction process, which are considered a good solution, being compact in size, efficient and flexible to different feed gas compositions [19]. A comparison and an optimization analysis of these two processes has been carried out in [20], where a model based on genetic algorithms has been proposed. The single mixed refrigerant process efficiency strongly depends on the optimization of mixed refrigerant composition and on the ambient conditions [21] and the power consumption of this process is usually lower than the $\mathrm{N}_{2}$ expander cycle one. On the other hand, the efficiency of the latter is almost independent of feed gas condition. Moreover, nitrogen is a nonreactive refrigerant, then the safety is greater [22]. In this context, and with the aim to develop a plug \& play LNG production system, in previous works, the Authors already examined the possibility of producing the LNG directly at the filling station developing a novel and simple small-scale plant [23].

With these premises, the main aims of the present study are (i) the development of a comprehensive procedure for the thermodynamic design and optimization, the engineering design and the off-design evaluation of small-scale LNG production processes and (ii) the application of the proposed procedure to an existing case study, in order to optimize its design and operation. In more detail, the first goal of the present paper is to develop a comprehensive procedure for assessing the configurations, design parameters, working conditions and off-design behavior that optimizes the performance of natural gas liquefaction systems, depending on the boundary conditions and constrains.

In short, this innovative procedure can be summarized considering three levels of approach:

1. the thermodynamic design and optimization (presented in Section 2) on a small-scale LNG production system, varying the values of the supply pressure, in order to identify the optimum layout and parameters (e.g., compressor pressure ratio, temperature and pressure in each plant section, etc.) that minimizes the total specific electric energy consumption (e);

2. the development of a model (Section 3) which, based on the parameters obtained in the thermodynamic optimization, allows to develop the engineering design and dimensioning of each component of the plant. The obtained results (i.e., compressor volumetric efficiency and displacement, etc.) are used as starting point for the off-design analysis;

3. the development of an off-design model (Section 3) that estimate the LNG system behavior when it is coupled with a renewable non programmable generator; 
In this study, this general procedure, which can be used for the design and the performance evaluation of a small scale LNG production plant, coupled with renewable generators, has been applied to a case study (Section 4) consisting in the installation of an LNG production plant at the port of Ravenna. In more detail, the optimal size of the renewable plant to be coupled with the LNG production system has been defined and the yearly operation of the integrated system has been evaluated.

\section{Thermodynamic Design and Optimization}

\subsection{Process Description}

A schematic representation of the LNG production layout is presented in Figure 1. It includes the basic processes for the liquefaction of the natural gas, i.e., a compression unit, a cooling section, an expansion device, a separation tank (flash tank) and a storage tank. The most generic case shall comprehend a secondary compression line to compress the recirculated vapor coming from the flash tank for the mixing with the fresh natural gas (NG) stream. As it will be better clarified in the following, the presence of a compression in the secondary line depends on the hypotheses and parameters assumed in the analysis, and in particular, on pressure values selected for the gas grid and for the storage tank. The cooling section is composed of an ammonia compression chiller and of two regenerative heat exchangers, where the low-pressure recirculated vapor is used to cool down the stream coming from the primary compression line.

To limit the consumption of the compressors, both compression lines are cooled by inter and after-coolers, whose optimized thermodynamic design was assessed in [24]. As an expansion device, a Joule-Thompson valve and a turbo-expander are alternatively considered in the simulations. The expander mechanical power is given to the compressors, leading to a reduction of the energy externally provided to the process; on the other side, the installation of an expander increases the investment costs, thus the energy savings must be consistent to support this option.

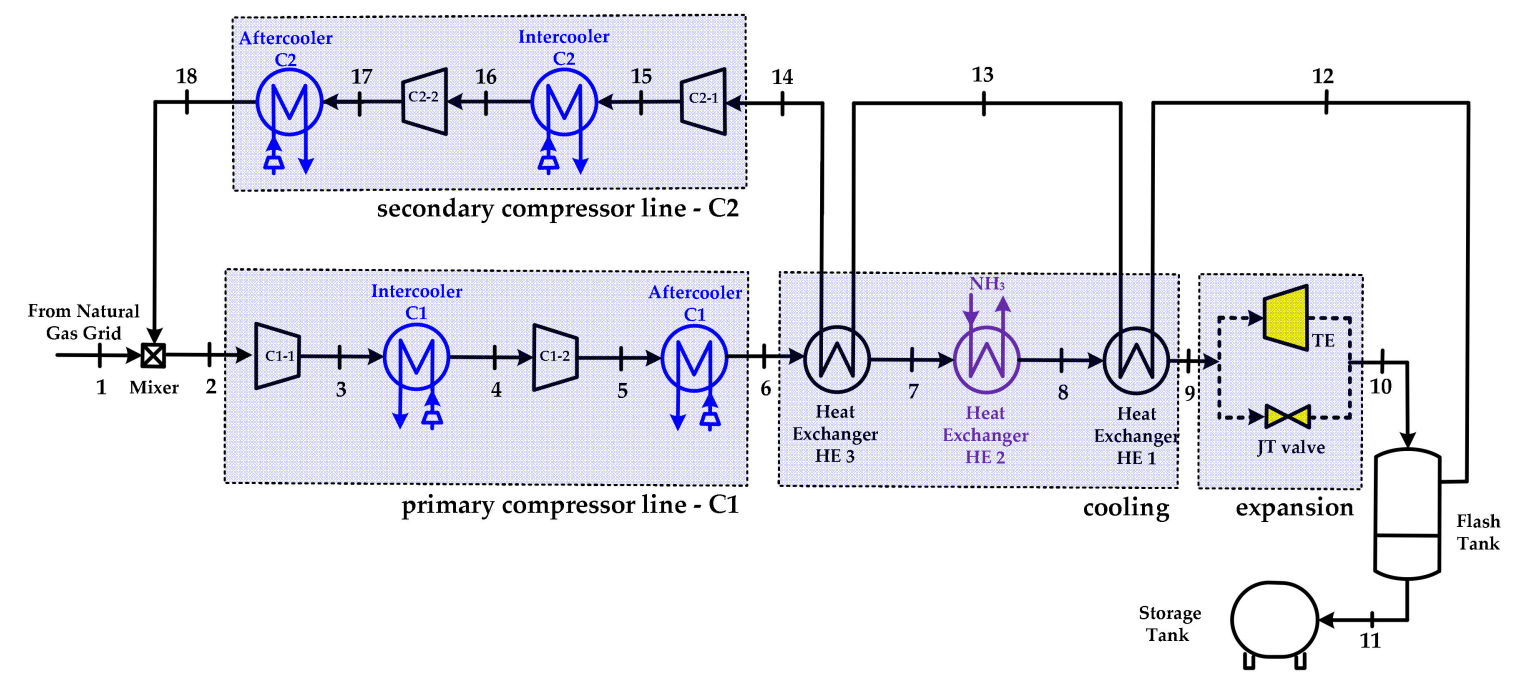

Figure 1. Schematic of the proposed small-scale liquefaction process.

\subsection{Thermodynamic Modeling}

The thermodynamic optimization was realized through a physical-mathematical model, developed in Visual Basic for Application (VBA) environment. In more detail, through an iterative procedure, the model allows to determine the optimal plant layout and the physical states (pressure, temperature and mass flow rate) of each sections in order to achieve the optimal values of the performance indicators usually considered for these power plants (as will be explained in the Section 2.3). Furthermore, by means of the iterative resolution of the developed thermodynamic model, a complete thermodynamic evaluation of the power plant is carried out by varying the key parameters affecting the performance of 
the plant, namely (i) the layout, (ii) the pressure at the exit of the primary compressor line $\left(\mathrm{p}_{6}\right)$ and (iii) the storage tank pressure $\left(\mathrm{p}_{10}\right)$. In particular, these last two parameters are varied between a minimum and a maximum value, and all their possible combinations are considered.

During the calculation, the developed model also defines the configuration of the secondary compressor line on the basis of the value of natural gas grid pressure. The second compressor line options are (with reference to Figure 1):

(1) compressor C2-1 and inter-cooler C2 + compressor C2-2 and after-cooler C2;

(2) compressor C2-1 and inter-cooler C2;

(3) no secondary compressor line.

Furthermore, depending on the considered value of the gas network supply pressure and for given values of the pressures at the exit of the primary compressor line and at the storage tank, the total compression ratio for each compression train is completely defined, if the pressure losses through the various heat exchanger are assumed. The developed model opportunely splits the total compression ratio between the two compressor stages by applying the minimum compressor specific work criterion. This criterion has been modified by the Authors [24] in order to take into account also the pressure losses through the compression train.

As it regards the cooling section, the components HE3 and HE1 are simply calculated by the method of logarithmic mean temperature difference, while HE2 performance is estimated by assuming a value of the temperature at the chiller outlet $\left(\mathrm{T}_{8}\right)$ as input.

Finally, it is possible to choose between the use of Joule-Thomson (JT) valve or a turbo-expander (TE) in the expansion section. In this last case, the expander performance is estimated by considering a constant value of isentropic efficiency.

For further details about the mathematical models adopted in this thermodynamic optimization tool, please refer to [24].

Four scenarios have been taken into account relating to the value of natural gas supply pressure:

- $\quad$ high pressure supply network, 70 bar (HPN),

- medium-high pressure supply network, 30 bar (MHPN),

- medium-low pressure supply network, 15 bar (MLPN),

- $\quad$ low pressure supply network, 3 bar (LPN)

According to the most common pressure values in the various branches of Italian national gas network [25].

Furthermore, the pressure at the exit of primary compressor line (i.e., the maximum pressure of the cycle) has been assumed varying between 150 bar and 300 bar, while the storage pressure ranges between 3 bar and 15 bar. These values have been chosen considering the current technology regarding the gas compressors and the available technology for LNG storage tanks on vehicles.

The main flow chart of the calculation model, which accomplishes the thermodynamic design and optimization phase (level 1) is presented in Section 3, as part of the complete procedure for the design and performance evaluation. In addition, further details on the thermodynamic optimization procedure can be found in [17].

\subsection{Performance Indicators}

As mentioned in Section 2.2, the aim of the thermodynamic optimization analysis is to find the layout and the thermodynamic parameters that allow to minimize the energy consumption, while maximizing the LNG production. To this purpose, the evaluation is made by means of the total specific electric energy consumption, $e$, already introduced in [24]. It is expressed in $\mathrm{kJ} / \mathrm{kg}$ and defined by Equation (1):

$$
e=\frac{P_{t o t}}{\dot{m}_{L N G}}
$$


where $P_{t o t}[\mathrm{~kW}]$ is the total electric power required by the whole liquefaction process and $\dot{m}_{L N G}[\mathrm{~kg} / \mathrm{s}]$ is the LNG produced mass flow rate. The amount of the consumed electric power corresponds to the power required by the two compression lines minus the power supplied by the expander, if installed:

$$
P_{\text {tot }}=P_{C 1}+P_{C 2}-P_{T E}
$$

For a fair comparison between the various cases, all the simulations are referred to a production of LNG equal to $1 \mathrm{~kg} / \mathrm{s}$, considering that all the results are scalable to different plant sizes. The quality of the NG in the flash tank, $\left(x_{f t}=\frac{m_{\text {vap }}}{m_{\text {tot }}}\right)$, is also taken into consideration as an indicator of the process performance, since it strongly influences the total consumption of the compressors. In fact, the higher the quality in the flash tank, the higher the fraction of vapor that needs to be compressed and recirculated to the compressor $\mathrm{C} 2$, which rises its required power, increasing also the flow rate and consumption of the compressor $\mathrm{C} 1$ due to the higher flow rate coming from the mixer. From a different viewpoint, at given mass flow rate of natural gas from the grid, the mass flow rate of produced LNG decreases at higher values of the fluid quality after the expansion.

\subsection{Hypothesis and Assumptions}

The main assumptions, that are common to all the considered cases, are collected in Table 1. In detail, the temperature of NG coming from the grid $\left(\mathrm{T}_{1}\right)$ is taken equal to $20^{\circ} \mathrm{C}$, regardless of value of the supply pressure. The temperature values at the outlet of inter and after-cooler on both the compression lines are set at $30^{\circ} \mathrm{C}$. Each compressor is characterized by polytropic efficiency of 0.63 and electromechanical efficiency equal to 0.90 . These values were imposed following previous evaluations on the performance of volumetric compressors for this kind of applications discussed in a previous Authors' study [24].

Regarding the cooling section, a temperature equal to $-50{ }^{\circ} \mathrm{C}$ is selected at the outlet of the chiller unit $\left(\mathrm{T}_{8}\right)$, whose Energy Efficiency Ratio (EER) is imposed equal to 1.1. The influence of the chiller outlet temperature on the cycle performance was evaluated by the Authors in [24], highlighting that this unequivocally affects the overall consumption of the circuit, which decreases as the outlet temperature decreases. The effectiveness of both the regenerative heat exchangers is assumed equal to 0.70, while the pressure drops through the various heat exchangers (including inter and after-coolers) are assumed equal to $2 \%$ [24]. Finally, the turbo-expander, when included in the layout, works with an isentropic efficiency equal to 0.70 . The natural gas composition of the stream coming from the grid is assumed as $100 \% \mathrm{CH}_{4}$. This approximation has negligible effects on the thermodynamic performance, as already underlined in previous Authors' study [24].

Table 1. Assumptions for parametric analysis.

\begin{tabular}{ccc}
\hline Parameters & Units & Values \\
\hline$T_{1}$ & {$\left[{ }^{\circ} \mathrm{C}\right]$} & 20 \\
$\dot{m}_{L N G}$ & {$[\mathrm{~kg} / \mathrm{s}]$} & 1 \\
$\eta_{\text {pol }}$ (each compressor) & {$[-]$} & 0.63 \\
$\eta_{\text {em }}$ (each compressor) & {$[-]$} & 0.90 \\
$\eta_{\text {is }}(\mathrm{TE})$ & {$[-]$} & 0.70 \\
Reg. HE effectiveness $(\varepsilon)$ & {$[-]$} & 0.70 \\
Chiller EER & {$[-]$} & 1.1 \\
Pressure losses (each HE) & {$[\%]$} & 2 \\
$T_{8}$ & {$\left[{ }^{\circ} \mathrm{C}\right]$} & -50 \\
$T_{\text {out intercooler/aftercooler }}$ & {$\left[{ }^{\circ} \mathrm{C}\right]$} & 30 \\
\hline
\end{tabular}




\subsection{Optimization Results}

The results of the design parametric analysis are shown in this section. For each supply pressure scenario, the best corresponding modified layout is presented, along with the set of parameters resulting from the optimization. The main difference in the cycle layout regards the secondary compression line $\mathrm{C} 2$, which can vary its configuration depending on the pressure ratio that needs to realize. Both the cases with the JT valve and with the turbo-expander are considered, in order to quantify the advantage in adopting an expansion device to produce mechanical power.

The resulting layouts are reported in Figure 2a-d, relative to the supply pressure scenarios HPN, MHPN, MLPN and LPN, respectively.

The high supply pressure (Figure 2a) concerns the main pipelines of the NG distribution network. It presents the advantage of reducing the pressure ratio operated by the primary compression line, thus decreasing the corresponding compression work. At the same time, the pressure difference between the storage pressure and the supply pressure results very high, increasing pressure ratio and power required by the secondary compressor line. The latter is also more complex, involving two stages of cooling (inter and after-cooler).

The optimized layout for a supply pressure equal to 30 bar (Figure $2 \mathrm{~b}$ ) hold the main difference with the previous case in the absence of the inter-cooler in the secondary compressor line. This is due to the lower difference between the storage pressure $\left(\mathrm{p}_{10}\right)$ and the supply pressure $\left(\mathrm{p}_{1}\right)$, that requires a lower compression work. The compressor $\mathrm{C} 2$ is now modelled with one unit refrigerated by an after-cooler.

The optimized layout of the medium-low supply pressure case (MLPN) provides for no compressor for the recirculation of NG vapor. Nevertheless, in Figure 2c the compression line C2 is still represented, since in the parametric analysis it was still necessary for storage pressures below 15 bar. Thus, the compressor $\mathrm{C} 2$ can be removed from the plant layout, determining a drop of power consumption and resulting the optimum configuration within the MLPN scenario. In addition, the costs of purchase and installation of the compression line are avoided, reducing the total investment for the liquefaction plant. On the other hand, clearly increasing the complexity and costs for the high-pressure storage facilities must be considered too.

In a low supply pressure case (LPN, Figure 2d), the secondary compression line C2 results unnecessarily within the whole parametric analysis because the pressure in the flash tank is always higher than the supply pressure. Rather, a lamination valve (V2) could be necessary to reduce the pressure in case of high storage pressure. The resulting layout is the simplest among the analyzed scenarios and this results in less complexity and number of components to be installed, less maintenance and lower investment cost.

The thermodynamic results of the sensitivity analysis are described by Figure 3a-d, that report the performance indicator $e$ and the quality of the fluid at the flash tank $\left(x_{\mathrm{ft}}\right)$ as function of the maximum pressure $\left(\mathrm{p}_{6}\right)$ and of the storage pressure $\left(\mathrm{p}_{10}\right)$, for the four supply pressure scenarios. In the 3D plots, the JT valve and the turbo-expander cases are represented, respectively, by the upper surface and by the lower one. In Table 2 the specific values of the parameters that allow the lowest consumption for the liquefaction process are collected, i.e., the values representing the minimum points of each surface in Figure 3a-d. Finally, in Figure $4 a-d$, the thermodynamic cycles related to each process are traced in pressure-enthalpy diagram. The following comments can be considered valid for all the four scenarios. 


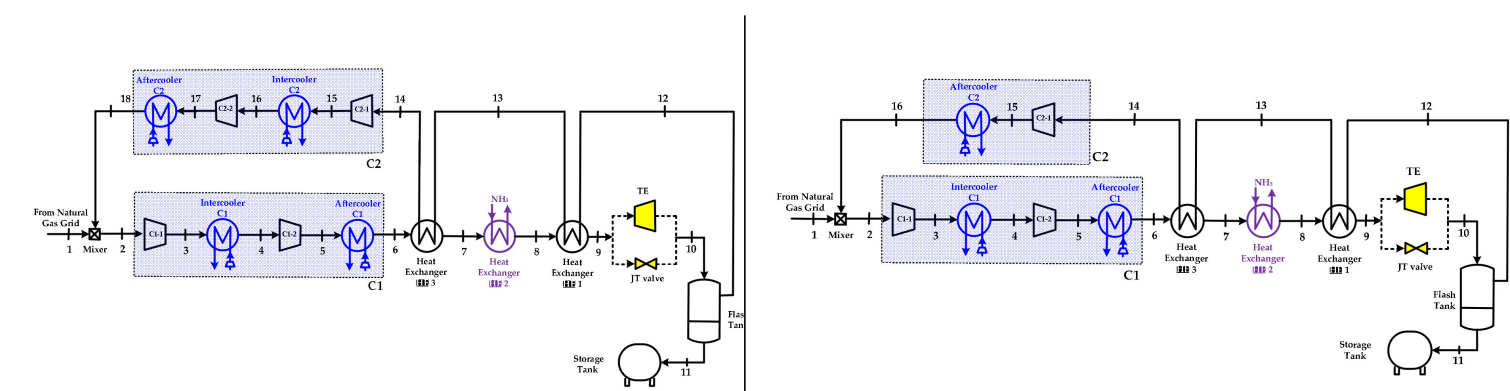

(a)

(b)

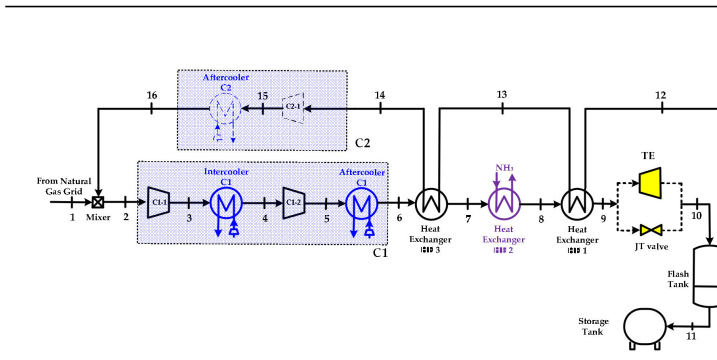

(c)

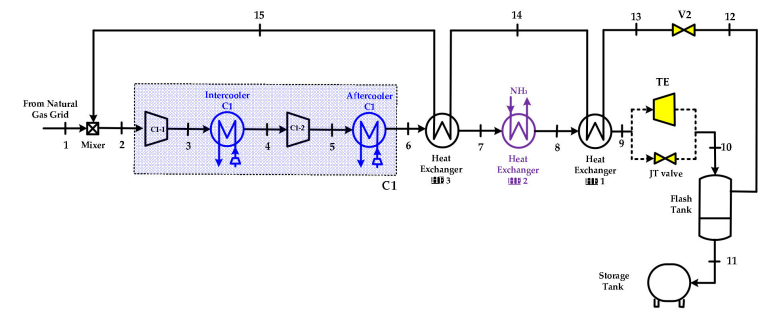

(d)

Figure 2. Optimum layouts for the considered supply pressure scenarios: (a) high pressure supply network (HPN), (b) medium-high pressure supply network (MHPN), (c) medium-low pressure supply network (MLPN), (d) low pressure supply network (LPN).

Table 2. Optimized results of parametric analysis.

\begin{tabular}{ccccccc}
\hline & & $\begin{array}{c}\mathbf{p}_{\text {sup }} \\
\left(\mathbf{p}_{\mathbf{1}}\right)\end{array}$ & $\begin{array}{c}\mathbf{p}_{\max } \\
\left(\mathbf{p}_{\mathbf{6}}\right)\end{array}$ & $\begin{array}{c}\mathbf{p}_{\text {stor }} \\
\left(\mathbf{p}_{\mathbf{1 0}}\right)\end{array}$ & $\mathbf{x}_{\mathbf{f t}}$ & $\begin{array}{c}\text { Total Specific Electric Energy } \\
\text { Consumption }(\boldsymbol{e})\end{array}$ \\
\hline \multicolumn{2}{c}{ Configuration } & {$[\mathrm{bar}]$} & {$[\mathrm{bar}]$} & {$[\mathrm{bar}]$} & {$[-]$} & {$\left[\mathrm{kJ} / \mathrm{kg}_{\mathrm{LNG}}\right]$} \\
\hline $\begin{array}{c}\text { Scenario } \\
\text { HPN }\end{array}$ & JT-HPN & \multirow{2}{*}{70} & 175 & 15 & 0.53 & 1489 \\
\hline TE-HPN & & 200 & 15 & 0.41 & $1092(-27 \%)$ \\
MHPnario & JT-MHPN & \multirow{2}{*}{30} & 150 & 15 & 0.55 & 1772 \\
\hline Scenario & JE-MHPN & & 170 & 15 & 0.43 & $1377(-22 \%)$ \\
MLPN & TE-MLPN & \multirow{2}{*}{15} & 150 & 15.6 & 0.55 & 1991 \\
\hline Scenario & JT-LPN & \multirow{2}{*}{3} & 160 & 15.6 & 0.44 & $1612(-19 \%)$ \\
LPN & TE-LPN & & 200 & 15 & 0.40 & 3263 \\
\hline
\end{tabular}




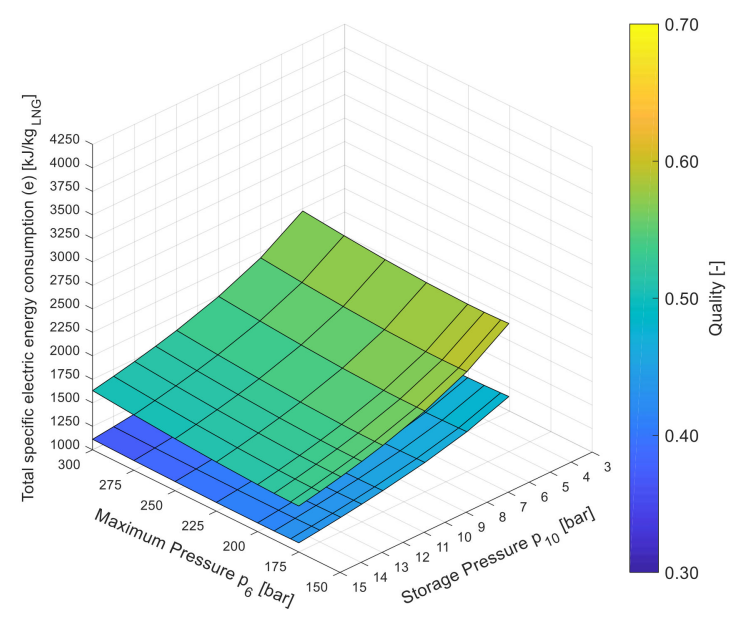

(a)

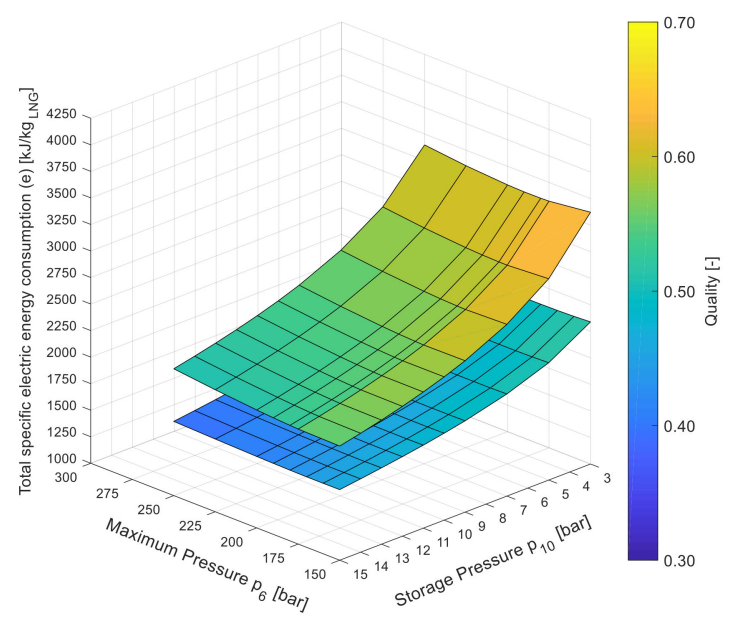

(c)

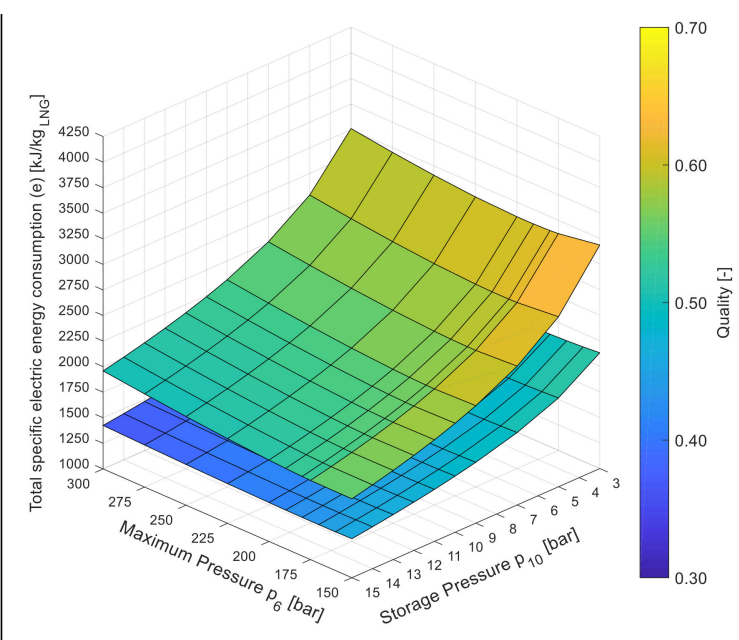

(b)

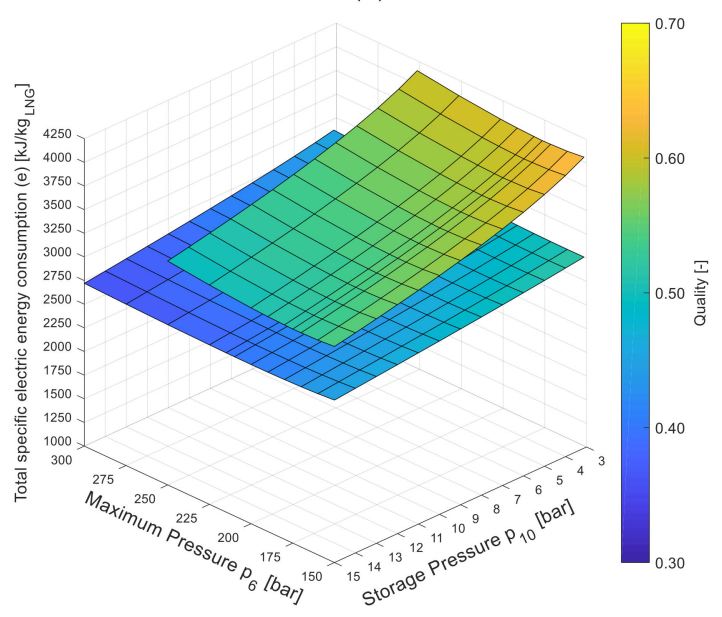

(d)

Figure 3. Total specific electric energy consumption as function of maximum pressure $\mathrm{p}_{6}$ and storage pressure $\mathrm{p}_{10}$ : (a) HPN, (b) MHPN, (c) MLPN, (d) LPN.

The impact of the adoption of the turbo-expander is significant, since it leads to a reduction of the total specific energy consumption between $27 \%$ and $18 \%$ (the percentage of energy savings decreases with the supply pressure reduction, see Table 2). The plots highlight a further advantage of replacing the lamination valve with an expander: the first solution, indeed, involves an isenthalpic process, while the second one causes a reduction of the enthalpy value, which implies also a lower quality of the natural gas at the end of the expansion, with consequent saving in energy consumption for the liquefaction process. However, the major impact on the specific energy consumption $e$ is given by the storage pressure $p_{10}$ : in fact, regardless of the maximum pressure $p_{6}$, the vapor quality in the flash tank decreases considerably with the increase of the storage pressure $\left(\mathrm{p}_{10}\right)$, reducing the fraction of recirculated NG as vapor and so the consumption of the compressors. This is due to the shape of the saturation curve and to the consistent reduction of the heat of vaporization, as the pressure rises from 3 bar to 15 bar. Obviously, also the power required by the compression chiller rises with the increment of the NG quality. It follows that, in all the scenarios, the optimized solution involves the maximum value of storage pressure within the considered range (3-15 bar). 
The influence of maximum pressure of the circuit, $\mathrm{p}_{6}$, appears less intuitive: being the total specific consumption a result of the sum of three different components having opposite characteristic curves, the representative equation is not a monotonic function and has a global minimum. Looking at the pressure-enthalpy diagrams in Figure $4 a-d$, at given temperature at the inlet of the expansion device, the consumption of the compressors is affected by the pressure ratio, which increases with $\mathrm{p}_{6}$, and by the mass flow rate of NG over the entire cycle, that is decreased because of the quality reduction. This occurs for values of pressure up to 220 bar, above which the advantage is no more relevant. The same trend is obtained both with the expansion valve and with the turbine.

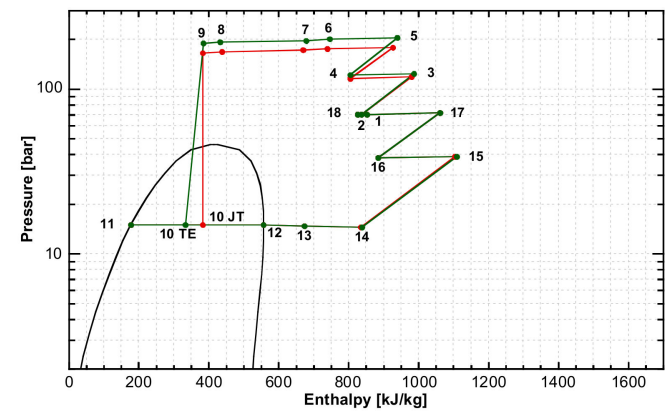

(a)

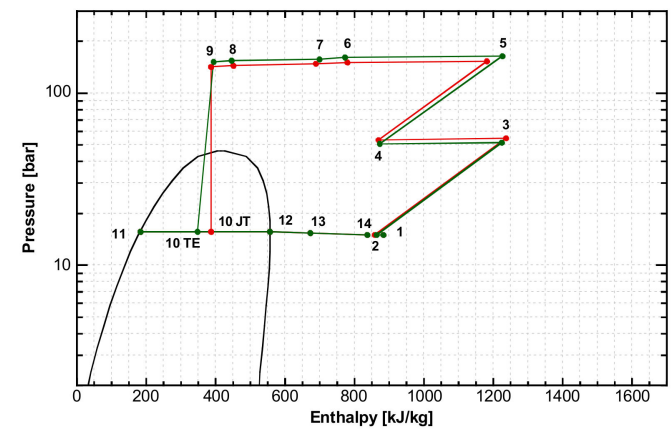

(c)

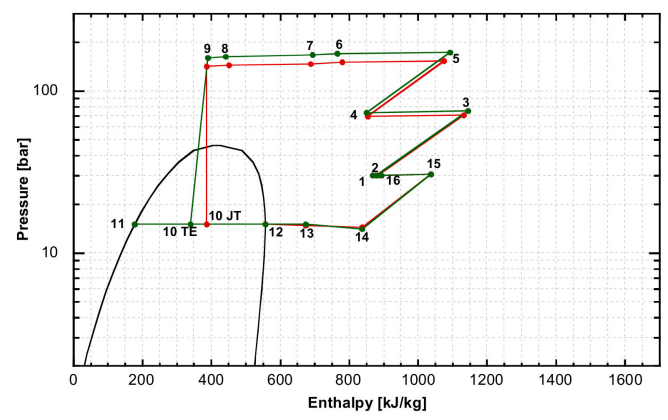

(b)

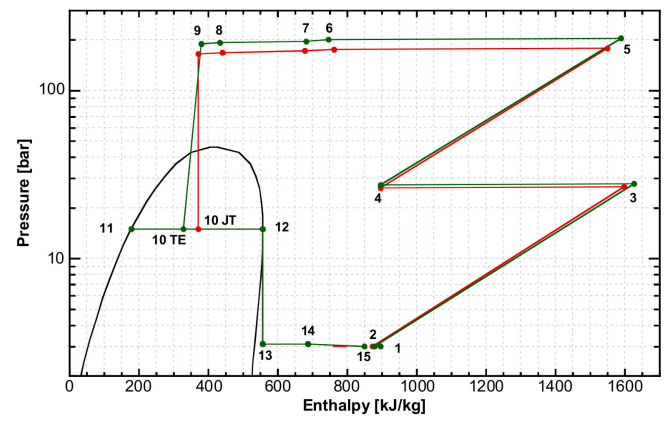

(d)

Figure 4. Optimum thermodynamic cycles in pressure-enthalpy diagram: (a) HPN, (b) MHPN, (c) MLPN, (d) LPN.

\subsection{Discussion on the Proposed LNG Production Process}

As already mentioned in the introduction of this work, the proposed LNG production process has been developed by Authors and presented in previous studies $[23,24,26]$ with the main aim to realize a plug \& play solution to be placed directly at vehicles and/or ships refueling stations. Indeed, small-scale LNG production facilities are currently rare and mainly realized in order to reduce the workload on gas reservoirs sites [26] or for offshore compact LNG production [27]. In this scenario, the idea of generating LNG directly at filling stations has been developed, in order to give a compact solution and to avoid the economic and environmental costs related to the LNG transportation by ship, contemporarily promoting LNG as fuel in transport sector. In addition, with respect to the processes usually employed in small-scale applications (i.e., $\mathrm{N}_{2}$ expander cycle and single-mixed refrigerant process), the proposed process is aimed at the realization of simpler-and, as a consequence-less expensive solutions, which can be competitive in the future global energy scenario. 
The proposed layout is general and can be easily adapted to different requirements in terms of boundary conditions. In particular, the secondary line (see Figure 1) can vary on the basis of the pressures of the natural gas network and of the storage tank, allowing to install the LNG production plant in a very wide range of conditions. In detail, the secondary line may include: (i) a compression train (with one or more compression stages, eventually inter-cooled) when the LNG storage pressure is lower than the NG network pressure, (ii) an isenthalpic valve when the LNG storage pressure is higher than the NG network pressure or (iii) no additional components when the LNG storage pressure and the NG network pressure differ only for the pressure drops through the line.

As it concerns the maturity level of technology, at present, a prototype of the LNG production process developed by the Authors has been realized and experimentally tested by the Italian Company Graf S.p.a., with the final aim to commercialize the technology [17]. Finally, the layout has been specifically developed for small-scale applications, namely for liquefaction facilities with a production capacity up to 1 MTPA (Mega Tons Per Annum). Below this value of capacity, the process is scalable and the simplicity of the solution can be maintained with economic convenience. On the other hand, for medium/large scale LNG production plants, the proposed process is not yet competitive with the commonly used technologies from an economic viewpoint.

In the following section, the calculation model, specifically developed for the proposed LNG production process, will be presented. In this respect, starting from this point, the expansion device considered for the continuation of the study is the lamination valve (JT layouts). To the Authors' opinion, indeed, this choice better reflects the current industrial state-of-the-art, since no commercial models of cryogenic expander are spread in the market yet. In more detail, at present, some prototypes of cryogenic expander are under development or at testing phase, as the advantage in saving consumption of replacing the JT valve with a turbine is indisputable. However, in order to give a larger scale applicability of the proposed approach, the developed off-design calculation model refers to JT expansion layouts for LNG production.

\section{Engineering Design and off Design Performance Evaluation}

The coupling of a small scale LNG production plant with non-programmable renewable generators involves the study of the off-design behavior of the system. This behavior is clearly influenced by the design point. For this reason, the off-design calculation model represents the third level of the developed design procedure after the definition of input, parameters and boundary conditions by the thermodynamic design and optimization phase (level 1, discussed in Section 2) and by the engineering design phase (level 2).

With reference to Figure 5, the thermodynamic design and optimization phase allows the definition of the plant layout and of the cycle thermodynamic parameters (pressures and temperatures) which guarantee the minimum value of total specific electric energy consumption as a function of the available NG supply pressure, assuming a range of variation of the maximum pressure and of the storage pressure. The output of this first evaluation level become the input of the calculation model for the engineering design of the LNG plant. In addition, the design values of the produced LNG mass flow rate and of the compressor rotating speed must be provided as calculation model input. It is important to point out that the engineering design model is based on the hypothesis to only use reciprocating compressor according to the evidence presented in $[17,23]$.

The main outputs of the engineering design calculation (see Figure 5) are:

- displacement of each compressor;

- design volumetric efficiency of each compressor;

- design isentropic efficiency of each compressor;

- design shaft power of each compressor;

- design NTU of each heat exchanger;

- total absorbed electrical power; 
- design natural gas consumption.

These last results will be used as input for the last level of calculation (off-design calculation in Figure 5) that is able to analyze the behavior of the plant as a function of the boundary conditions. In more detail, the realized model was used in this study to calculate the LNG produced mass flow rate of the plant as a function of the available electrical power from a given non-programmable renewable generator.

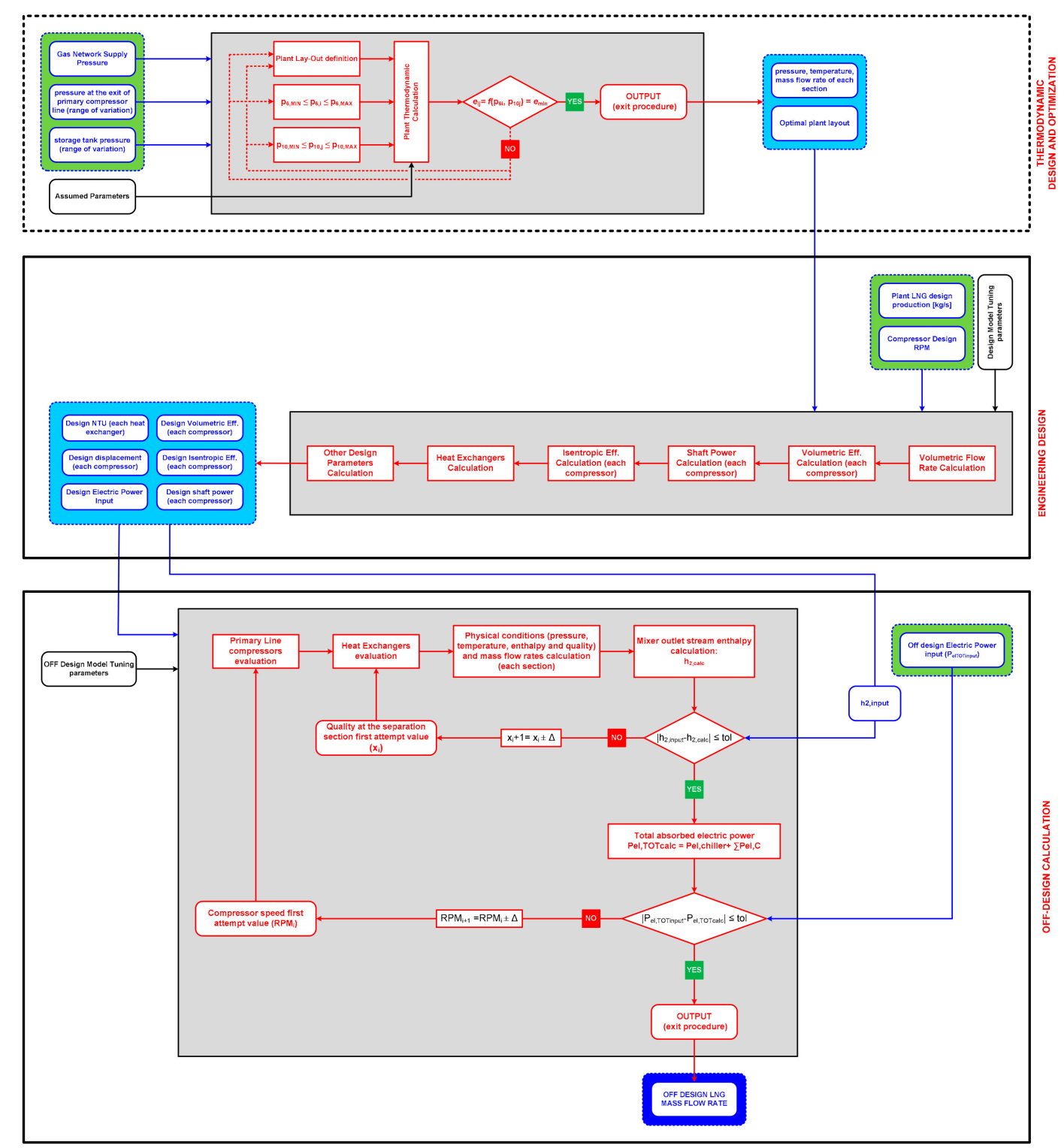

Figure 5. Flow chart of the developed calculation procedure consisting in (i) thermodynamic design and optimization, (ii) engineering design and (iii) off-design calculation.

\subsection{Engineering Design Mathematical Model}

In this study, a validated semi-empirical method for volumetric reciprocating compressors coming from the literature $[28,29]$ is employed to calculate mass flow rate, power input and temperature at the end of each compression section. This method provides an integration between physical-based models for compressors at design speed and a polynomial approach for compressor efficiency at off-design speed. 
First of all, as a starting point for the off-design calculation, the applied compressor model defines the involved physical quantities at the design point (Equations (3)-(11)), which can be calculated on the basis of the optimal results obtained by the thermodynamic analysis presented in Section 2 and of the equations presented in [28]. In more detail, based on the physical conditions (i.e., temperature and pressure) and on the mass flow rate at the inlet of each compressor $(\dot{m},[\mathrm{~kg} / \mathrm{s}])$, the suction volumetric flow rate $\left(\dot{V}_{\text {suc,des }},\left[\mathrm{m}^{3} / \mathrm{s}\right]\right)$ can be calculated as:

$$
\dot{V}_{\text {suc,des }}=\frac{\dot{m}}{\rho}
$$

where $\rho=f(p, T)$ is the density of the fluid at the inlet of the compressor, expressed in $\left[\mathrm{kg} / \mathrm{m}^{3}\right]$.

Furthermore, based on [28], the volumetric efficiency $\left(\eta_{V, \text { des }}\right)$ can be calculated by the following equation:

$$
\dot{V}_{\text {suc }, \text { des }}=\frac{\dot{m}}{\rho} \eta_{V, d e s}=\mathrm{b}_{1}+\mathrm{b}_{2}\left[\left(\frac{p_{\text {dis }}}{p_{\text {suc }}(1-\mathrm{dp})}\right)^{1 / k}\right]
$$

where $p_{\text {dis }}[\mathrm{kPa}]$ is the discharge pressure (evaluated from the imposition of the compressor pressure ratio), $p_{s u c}[\mathrm{kPa}]$ is the suction pressure, $k$ is the isentropic coefficient and $b_{1}, b_{2}$ and dp are model parameters [28].

As a consequence, for known compressor speed $\left(N_{d e s},[\mathrm{~Hz}]\right)$ and starting from the definition of the volumetric efficiency (Equation (5)), the compressor displacement $\left(V_{\text {disp }},\left[\mathrm{m}^{3}\right]\right)$ can be calculated by means of the Equation (6).

$$
\begin{gathered}
\eta_{V, \text { des }}=\frac{\dot{V}_{\text {suc,des }}}{N_{\text {des }} V_{\text {disp }}} \\
V_{\text {disp }}=\frac{\dot{V}_{\text {suc,des }}}{N_{\text {des }} \eta_{V, \text { des }}}
\end{gathered}
$$

Thus, the compressor shaft power $\left(W_{\text {des }},[\mathrm{kW}]\right)$ can be calculated as:

$$
W_{d e s}=\frac{1}{\eta_{o}} p_{s u c} \dot{V}_{s u c, d e s} a_{1}\left[\left(\frac{p_{d i s}}{p_{s u c}}\right)^{a_{2}+\frac{k-1}{k}}+\frac{a_{3}}{p_{d i s}}\right]
$$

where $a_{1}, a_{2}$ and $a_{3}[\mathrm{kPa}]$ are three model parameters [29]. Furthermore, in Equation (7), a power loss is accounted (by means of the coefficient $\eta_{0}$ ): as evaluated in the semi-empirical model presented in [28], indeed, a power loss equal to the $2 \%$ is registered.

Once evaluated, the compressor shaft power, the isentropic efficiency $\left(\eta_{i s, d e s}\right)$ can be calculated by means of the following equation:

$$
\eta_{i s, d e s}=\frac{\dot{V}_{s u c, d e s}\left(h_{i s}-h_{s u c}\right)}{v_{s u c} W_{d e s}}
$$

where $h_{i s}$ is the discharge enthalpy in an isentropic process $[\mathrm{kJ} / \mathrm{kg}], h_{s u c}$ is the suction enthalpy $[\mathrm{kJ} / \mathrm{kg}]$, $v_{s u c}=\frac{1}{\rho}$ is the suction specific volume $\left[\mathrm{m}^{3} / \mathrm{kg}\right]$. All these quantities are known from the previously presented thermodynamic analysis.

The evaluation of the discharge temperature (i.e., the temperature at the end of the compression section), finally, starts from the shell temperature $\left(T_{\text {shell }},[\mathrm{K}]\right)$, defined as shown in Equation (9):

$$
T_{\text {shell }}=\mathrm{c}_{1}+\mathrm{c}_{2} \frac{p_{\text {dis }}}{p_{\text {suc }}}+\mathrm{c}_{3} / p_{\text {dis }}
$$

where $c_{1}[K], c_{2}[K]$ and $c_{3}[K \cdot k P a]$ are three model parameters [28]. 
Then, the heat transfer to the ambient $\left(\dot{Q}_{a m b},[\mathrm{~kW}]\right)$ is evaluated by means of the following expression:

$$
\dot{Q}_{a m b}=\mathrm{US}_{\text {shell }}\left(T_{\text {shell }}-T_{\text {amb }}\right)
$$

where $\mathrm{US}_{\text {shell }}[\mathrm{kW} / \mathrm{K}]$ is a model parameter and $T_{\text {amb }}$ is the ambient temperature $[\mathrm{K}]$.

Finally, the discharge temperature can be calculated from the discharge enthalpy $\left(h_{d i s},[\mathrm{~kJ} / \mathrm{kg}]\right)$ :

$$
h_{d i s}=h_{s u c}+\frac{W-\dot{Q}_{a m b}}{\dot{m}}
$$

The compressor model parameters employed in this study come from a dataset [30] of a reciprocating compressor and are listed in Appendix A.

Furthermore, as it regards heat exchangers, Equations (12)-(15) represent the design point. As well-known, the heat exchangers behavior at the design conditions is governed by the heat exchange Equation (12) and it can be described by the $\varepsilon$-NTU method, where $\varepsilon$ is the heat exchanger effectiveness and NTU is the number of transfer units. In detail, the thermal exchange $\left(\dot{Q}_{H E, d e s},[\mathrm{~kW}]\right)$ is evaluated with the equation:

$$
\dot{Q}_{H E, \text { des }}=\dot{m}_{\text {des, } h} c_{p, h} \Delta T_{h}=\dot{m}_{\text {des, },} c_{p, c} \Delta T_{c}=U S \Delta T_{m l}
$$

where $\dot{m}_{\text {des }}$ is the mass flow rate $[\mathrm{kg} / \mathrm{s}], c_{p}$ is the specific heat in an isobaric process $[\mathrm{kJ} / \mathrm{kg} \cdot \mathrm{K}], \Delta T$ is the temperature difference $[\mathrm{K}], U$ is the global heat transfer coefficient $\left[\mathrm{kW} / \mathrm{m}^{2} \mathrm{~K}\right]$ and $S$ is the heat exchanger surface $\left[\mathrm{m}^{2}\right]$. Subscripts $h$ and $c$ refers respectively to hot and cold sides.

Then, in order to evaluate $\varepsilon$ and NTU parameters in design conditions, the heat capacity $\left(\dot{C}_{d e s}\right)$, expressed in $[\mathrm{kW} / \mathrm{K}]$, should be introduced:

$$
\dot{C}_{d e s}=\dot{m}_{d e s} c_{p}
$$

Finally, by means of Equations (14) and (15), the heat exchangers in design conditions can be completely evaluated.

$$
N T U_{\text {des }}=\frac{U_{\text {des }} S}{\dot{C}_{\text {min, des }}}=\frac{\Delta T_{\text {max }}}{\Delta T_{\text {ml,des }}}
$$

where $\Delta T_{m l, d e s}$ is the mean logarithmic temperature difference $[\mathrm{K}], \dot{C}_{m i n, d e s}$ is the minimum (between hot and cold sides) heat capacity $[\mathrm{kW} / \mathrm{K}]$ and $\Delta T_{\max }$ is the maximum (between hot and cold sides) temperature difference $[\mathrm{K}]$.

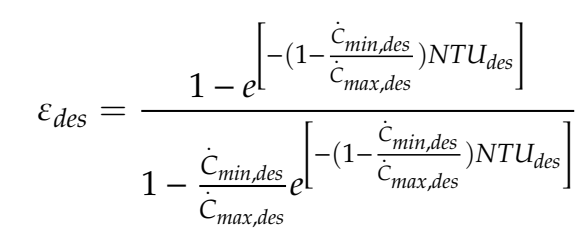

where $\dot{C}_{\max , \text { des }}$ is the maximum (between hot and cold sides) heat capacity $[\mathrm{kW} / \mathrm{K}]$.

\subsection{Off-Design Calculation Model}

Once the physical quantities in design conditions have been calculated, the compressors off-design analysis is carried out by means of Equations (16) and (19). According to [28], the normalized volumetric and isentropic efficiencies are influenced only by the normalized compressor speed and are independent from the pressure ratio. Then, the two efficiencies can be represented as a function of the normalized compressor speed through a second order polynomial function (Equations (16) and (17)):

$$
\frac{\eta_{v}}{\eta_{v, d e s}}=\mathrm{d}_{1}+\mathrm{d}_{2}\left(\frac{N}{N_{\text {des }}}\right)+\mathrm{d}_{3}\left(\frac{N}{N_{\text {des }}}\right)^{2}
$$




$$
\frac{\eta_{i s, d e s}}{\eta_{i s}}=\mathrm{e}_{1}+\mathrm{e}_{2}\left(\frac{N}{N_{\text {des }}}\right)+\mathrm{e}_{3}\left(\frac{N}{N_{\text {des }}}\right)^{2}
$$

where $d_{1}, d_{2}$ and $d_{3}, e_{1}, e_{2}$ and $e_{3}$ are model parameters [29].

Consequently, the volumetric flow rate in off-design conditions can be calculated from Equations (5) and (16) as it follows:

$$
\dot{V}_{\text {suc,off-design }}=\dot{V}_{\text {suc,des }} \frac{N}{N_{\text {des }}} \frac{\eta_{v}}{\eta_{v, \text { des }}}=\dot{V}_{\text {suc,des }}\left[\mathrm{d}_{1}\left(\frac{N}{N_{\text {des }}}\right)+\mathrm{d}_{2}\left(\frac{N}{N_{\text {des }}}\right)^{2}+\mathrm{d}_{3}\left(\frac{N}{N_{\text {des }}}\right)^{3}\right]
$$

Furthermore, from Equations (8) and (17), the compressor shaft power in off-design conditions is evaluated as:

$$
\begin{aligned}
W_{o f f-d e s i g n} & =W_{\text {des }} \frac{\dot{V}_{\text {suc }, o f f-d e s i g n}}{\dot{V}_{\text {suc,des }}} \frac{\eta_{i s, \text { des }}}{\eta_{\text {is }}} \\
& =W_{\text {des }} \frac{\dot{V}_{\text {suc, off-design }}}{\dot{V}_{\text {suc,des }}}\left[\mathrm{e}_{1}+\mathrm{e}_{2}\left(\frac{N}{N_{\text {des }}}\right)+\mathrm{e}_{3}\left(\frac{N}{N_{\text {des }}}\right)^{2}\right]
\end{aligned}
$$

As for the design section, the compressor model parameters come from the dataset reported in [30] and are listed in Appendix A.

Finally, it should be highlighted that the calculation model of the temperature at the end of the compression section in design conditions (Equations (12)-(15)) can be directly applied also to off-design conditions without any modification, since the model relies on system energy balance taking into account the heat transfer loss to the ambient.

On the other hand, in off-design conditions, the heat exchanger behavior cannot be described by $\varepsilon$-NTU method, but it is still governed by fluids energy balance and heat exchange equation, adjusted to the new operating conditions (Equations (20)-(22)). Evidently, considering the off-design of a specific heat exchanger, the exchange surface remains unchanged. As a consequence, the relationship between the thermal flows can be expressed only on the basis of the ratio between the products of global heat transfer coefficients and mean logarithmic temperature differences (Equation (20)):

$$
\frac{Q_{H E}}{Q_{H E, d e s}}=\frac{U}{U_{d e s}} \frac{\Delta T_{m l}}{\Delta T_{m l, d e s}}
$$

Being:

$$
\frac{U}{U_{d e s}}=\left(\frac{\dot{m}}{\dot{m}_{d e s}}\right)_{w}^{0.8}
$$

where the subscript $w$ is referred to the fluid with the worst convective heat transfer coefficient. Note that the exponent can slightly vary based on the considered fluids, the type of flow and the system geometry.

After the calculation of the global heat exchange coefficient, in off-design conditions $(U)$, the NTU parameter can be determined as it follows:

$$
N T U=U S / C_{\min }
$$

Finally, the heat exchanger effectiveness at off-design conditions $\left(\varepsilon^{\prime}\right)$ is still defined by Equation (15).

\section{Case Study: A LNG Refueling Station for Maritime Applications}

In this section, the calculation procedure presented in the previous paragraphs is applied to a real case study, consisting in the project—funded by the Emilia Romagna region and developed by the University of Bologna - to realize a LNG refueling station at the port dock of Ravenna (Italy) for maritime applications [31]. At present, a ferry is used to carry cars from one side to the other of the main canal of the Ravenna port ( $400 \mathrm{~m}$ wide) at a maximum rate of 10 runs per hour, for a total of $19 \mathrm{~h}$ per day in the whole year. The ferry is equipped with two diesel engines of $162 \mathrm{~kW}$ each. 
The developed idea entails the modification of the two engines into dual fuel engines working with LNG and diesel fuels. From the design of the new propulsion system [31], the single-engine power is supposed to decrease down to $125 \mathrm{~kW}$ at $1500 \mathrm{rpm}$. The ferry will be further equipped with four storage tanks of $3300 \mathrm{~L}$ each, operating at a pressure equal to $3 \mathrm{bar}$, refueled approximatively every week. Therefore, the LNG system must produce less than $4000 \mathrm{~kg}$ per week.

Starting from this idea, and accounting for these constraints, the first objective was to properly design the required LNG production plant. Furthermore, it is supposed that all the electrical energy required to move the compressors and the compression chiller is provided by renewable energy sources (in particular, wind). In this respect, the evaluation of optimal size of the wind plant, which allows to weekly produce the required amount of LNG, is also object of the presented analysis. In more detail, in the next paragraphs, the definition of the LNG production plant configuration and operating parameters-based on the optimization analysis presented in the Section 2 of this paper-and the application of the developed calculation model in order to define the optimal coupling with a wind plant will be presented and discussed. To this respect, it should be highlighted that the integration between the LNG production process and a wind plant is particularly interesting in order to promote the renewable sources exploitation without posing issues to the national electrical grid (such as frequency instability, capacity challenges, etc.). However, this has to be intended just as a possibility, while the proposed LNG production process and the design and performance methodology are valid independently from the source of the electricity which feeds the process.

Future works, after the realization of the proposed integrated plant, will analyze the real plant operation and the relative experimental results.

\subsection{LNG Production Plant Configuration and Assumptions}

Based on the grid pressure levels available on the installation site, the value of 3 bar was chosen as supply pressure, thus the corresponding optimized layout resulting from the application of the thermodynamic design and optimization model is the one shown in Figure $2 \mathrm{~d}$ with the Joule-Thompson valve for the LNG production. As already explained, indeed, the choice of considering the JT valve instead of the turbo-expander has been made considering the current technology development.

For the sake of completeness, the optimal values of the thermodynamic parameters assumed to design the LNG plant and kept constant for the whole off-design analysis are reported in Table 3.

As it regards the LNG production plant, it has been sized in order to be able to produce the required weekly amount of LNG with a security factor around 2 (corresponding to about 80 equivalent hours/week of operation). Based on these considerations, the LNG design mass flow rate was set at about $47 \mathrm{~kg} / \mathrm{h}(0.013 \mathrm{~kg} / \mathrm{s})$.

Table 3. Constant thermodynamic parameters for the design and off-design analysis (plant sections with reference to Figure 2d).

\begin{tabular}{cc}
\hline Parameter & Value \\
\hline NG composition & $100 \% \mathrm{CH}_{4}$ \\
$T_{1}$ & $20{ }^{\circ} \mathrm{C}$ \\
$p_{1}$ & $3 \mathrm{bar}$ \\
$T_{2}$ & $-5{ }^{\circ} \mathrm{C}$ \\
$p_{2}$ & $3 \mathrm{bar}$ \\
$p_{3}$ & $25 \mathrm{bar}$ \\
$p_{5}$ & $175 \mathrm{bar}$ \\
EER chiller & 1.1 \\
$T_{8}$ & $-50{ }^{\circ} \mathrm{C}$ \\
$p_{11}$ & $15 \mathrm{bar}$ \\
$T_{4}$ & $30{ }^{\circ} \mathrm{C}$ \\
$T_{6}$ & $30{ }^{\circ} \mathrm{C}$ \\
$T_{a m b}$ & $15{ }^{\circ} \mathrm{C}$ \\
\hline
\end{tabular}


The assumed compressor velocity, instead, was chosen equal to 1500 RPM according with the actual state of the art for what regards the compression of natural gas in the selected range of mass flow rate.

By the application of the engineering design calculation model, in the basis of the results of the thermodynamic analysis and of the values of LNG mass flow rate and compressor rotational speed, it follows a power plant in design condition with an electrical power consumption slightly higher than $43 \mathrm{~kW}$. Some of the results of the developed calculation are presented in Table 4, while an example of engineering design procedure can be found in the Appendix A of this paper.

Table 4. Design parameters of the LNG production plant resulting from the optimization analysis.

\begin{tabular}{cc}
\hline Parameter & Value \\
\hline$P_{e l, C 1}$ & $17.81 \mathrm{~kW}$ \\
$P_{e l, C 2}$ & $19.51 \mathrm{~kW}$ \\
$P_{\text {chiller }}$ & $6.02 \mathrm{~kW}$ \\
$P_{\text {el,tot }}$ & $43.34 \mathrm{~kW}$ \\
$\dot{m}_{L N G}$ & $0.013 \mathrm{~kg} / \mathrm{s}$ \\
\hline
\end{tabular}

On the basis of the previous results, the application of the off-design model allows the drawn the curves in Figures 6 and 7.

In more detail, Figure 6 shows the electric energy consumption of the compressors and of the chiller separately, as a function of the total electrical load of the system (i.e., the electric power required by the whole liquefaction process). As it can be noted, starting from the design point, the calculation model shows upper and lower operating limits for off-design conditions. In particular, the operating range can vary from $40 \%$ to $200 \%$ of the design electric load (this range derives from the operating range of the compressors). As it can be noted, the upper limit seems to be a quite high value and probably in real operation it cannot be reached, but it is presented here in order to show the validity range of the model. Furthermore, in Figure 7 the LNG produced mass flow rate are shown as a function of the plant load: an increase in this quantity with the electric load increase can be observed (with a variation relating to the design point from a minimum of $-53 \%$ to a maximum of about $+62 \%$ ), since the electric energy available to the compressors is higher.

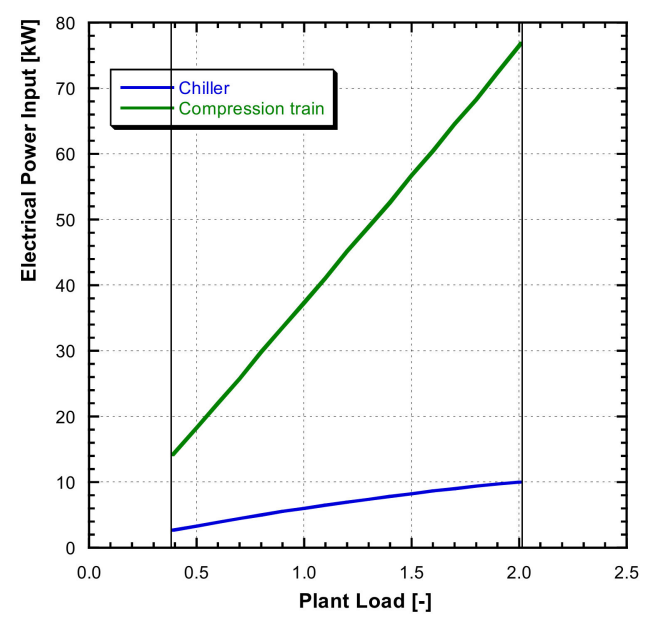

Figure 6. Non dimensional electric energy consumption of compressors and chiller as a function of the total electrical input. 


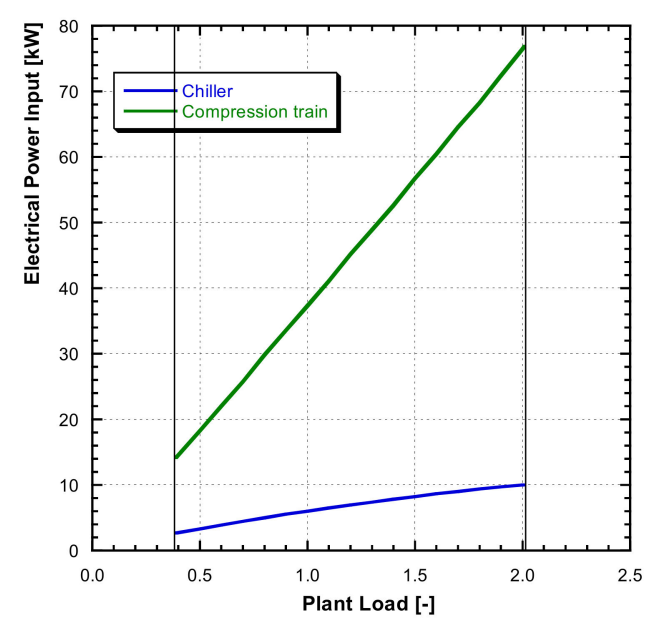

Figure 7. Non dimensional total specific energy consumption and the LNG produced mass flow rate, as a function of the total electrical input.

\subsection{Wind and LNG Plants Integration}

Once the configuration and the size of the LNG plant and the off-design behavior are known, the objective was the determination of the optimal size of a wind plant to be integrated into the system in order to provide the required electricity for the liquefaction process. Since, for the specific application, a certain amount of LNG must be guaranteed every week, the optimal wind size has been determined accounting for the plant operation during a whole year.

As a consequence, with this purpose, the production data of existing wind farms and the ones available from TERNA [32], related to the whole Italian territory, have been considered. Thus, starting from these data, the normalized wind production profile (on an hourly basis) has been obtained (Figure 8).

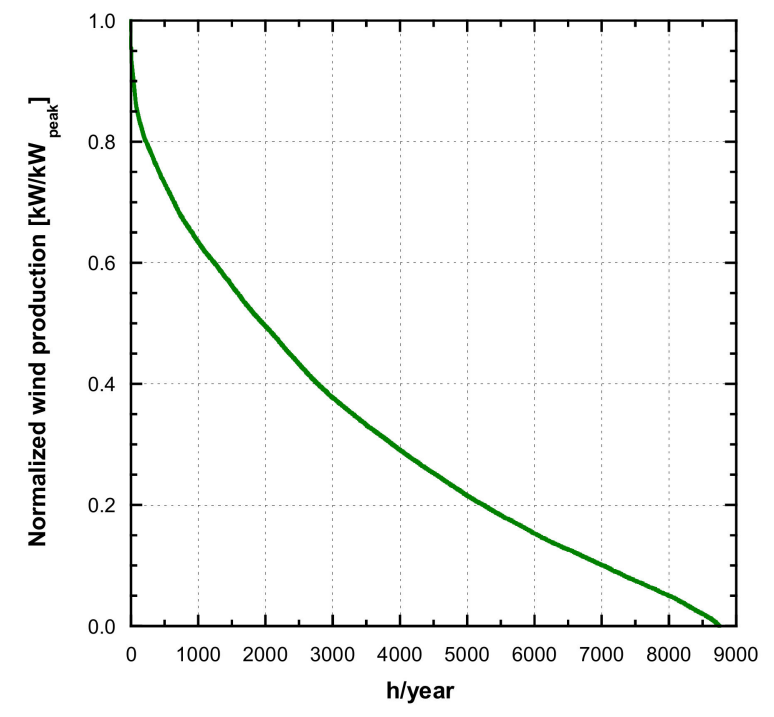

Figure 8. Normalized wind production profile [32].

Then, a dedicated code, developed in VBA, has been developed in order to consider the coupling between wind and LNG plants: the objective was the determination of the wind size, which allows contemporarily to respect the constraint of LNG production (around $4000 \mathrm{~kg} /$ week every week per year) and to minimize the electricity introduction into the national electric grid. The developed code, indeed, allows to evaluate the yearly operating time of the LNG production process, the surplus of 
electric energy not used by the plant—and then introduced into the electric grid—and the total specific electric energy consumption as a function of the wind plant size. In more detail, the code-for each considered wind plant size-analyzes the coupling of the wind and LNG plants for a whole year, hourly based:

- $\quad$ if, in the considered hour, the electrical production of the wind plant is lower than the lower operating limit of the LNG production process, then all the electric energy is introduced into the electric grid;

- $\quad$ if, in the considered hour, the electrical production of the wind plant is within the operating range of the LNG plant, then all the electric energy is employed in the process;

- if, in the considered hour, the electrical production of the wind plant is higher than the upper operating limit of the LNG production process, then the difference between the wind electric energy and the maximum electric load of the LNG plant is introduced into the electric grid.

The results of the coupling LNG and wind plants analysis are shown in Figure 9, in terms of the yearly LNG production (red curve) and electricity surplus to be sold to the grid (green curve), as a function of the wind size. As it can be seen, the wind size which allows to produce the LNG amount yearly required (about $4000 \mathrm{~kg}$ every week for a total of about 208,000 kg/year) is equal to about $78 \mathrm{~kW}$. In this case, the electric energy surplus to be yearly sold to the grid results equal to a value slightly lower than $33 \mathrm{MWh} /$ year. For wind sizes lower than $78 \mathrm{~kW}$, the mass of LNG produced does not fit with the ferry needs constraint and, consequently, should not be considered for this case study. On the other hand, for higher wind sizes, an excess of LNG production is seen with respect to the case study constraint. However, it should be highlighted that, for wind sizes higher than the one selected as the optimal for the presented case study, a further decrease in electricity excess to be sold to the network is registered. This behavior can be explained considering the upper limit of the operational range of the compressors.

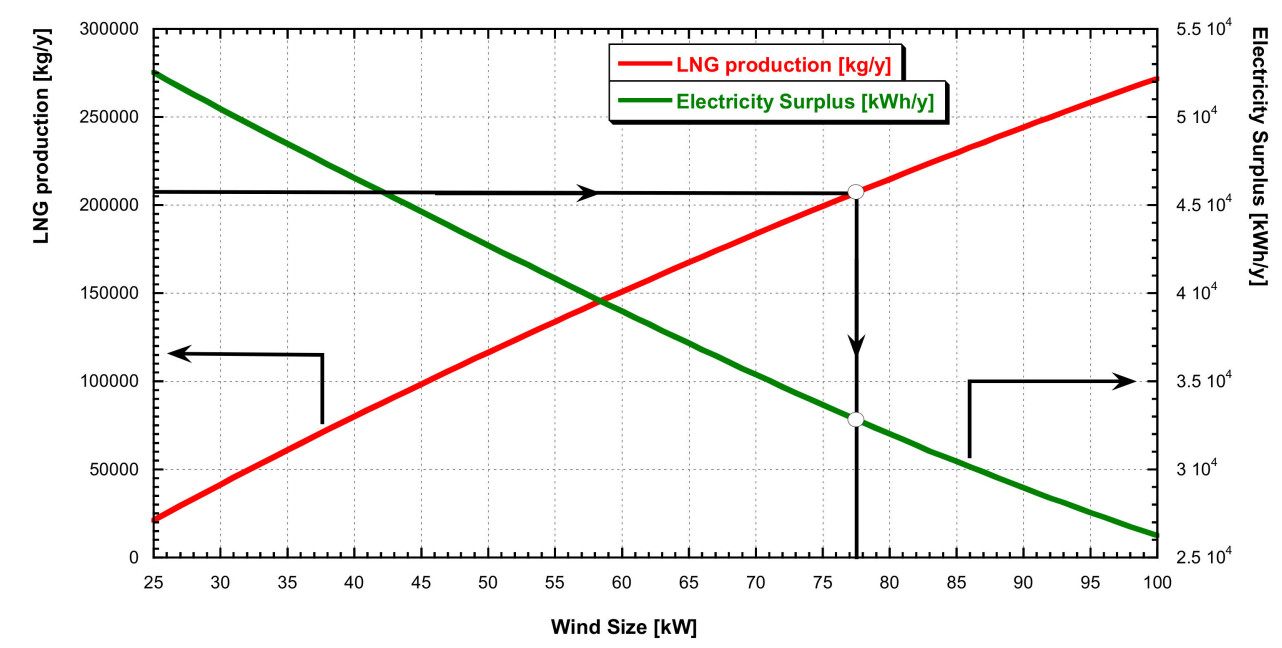

Figure 9. Yearly LNG production and energy surplus (to be sold to the grid) as a function of the wind size.

Finally, in order to evaluate the LNG plant hours of operation, the wind production during a year is shown in Figure 10. As it can be seen, the LNG plant-during a whole year of operation-works for $187 \mathrm{~h} /$ year in design conditions and for $4720 \mathrm{~h} /$ year in off-design, split between $1455 \mathrm{~h} /$ year in which the electrical input is higher than the rated electrical power and $3265 \mathrm{~h} /$ year in which the electrical input is lower. On the other hand, for $3853 \mathrm{~h} /$ year the LNG plant is shut-down because the wind production is below the lower operating limit of the LNG plant. On the other hand, as a confirmation of the results shown in Figure 9 for the electricity yearly sold to the network, the upper operating limit is not reached with the selected wind size. 


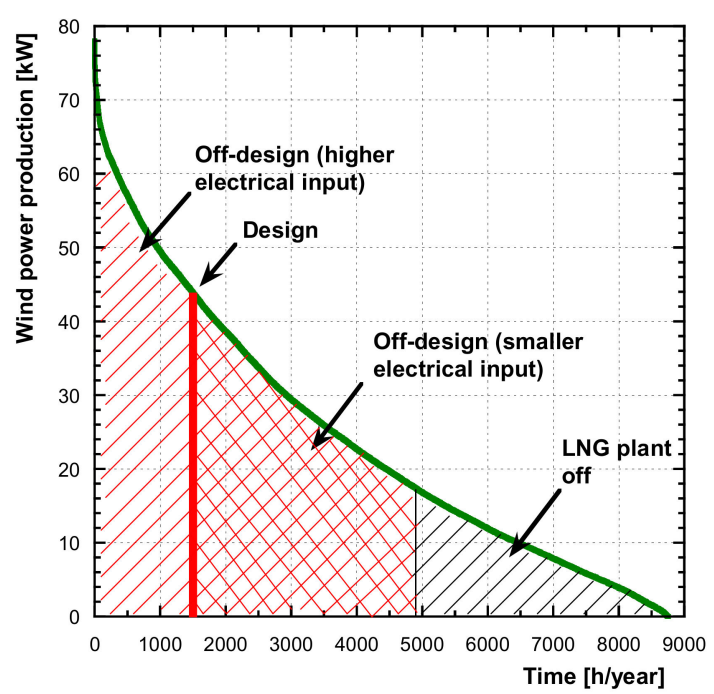

Figure 10. Hours of operation, during a year, of the LNG production plant.

\section{Concluding Remarks}

The liquefied natural gas (LNG) can be adopted as an alternative to traditional fuels in the transport sector, to reduce the related costs and pollutant emissions. The adoption of small-scale liquefaction systems directly installed at the filling station is a solution for avoiding transportation costs, which have large impact on the whole LNG value chain. In this study, a numerical investigation on small-scale LNG production plants is performed, with the aim of assessing the best conditions that minimize the total consumption of the process, both in design and off-design behavior. A three-levels calculation code has been developed, in order to (i) optimize the layout and thermodynamic parameters, (ii) develop the engineering design and dimensioning of each component of the plant and (iii) analyze the plant operation in off-design conditions (represented in this study by the variation of the electric power input, due to the coupling with renewable non-programmable sources). In more detail, at the first level of the proposed procedure, a thermodynamic analysis is conducted for selecting the optimal layout and design parameters (optimal pressure and temperatures in each section of the plant), for various scenarios of the supply pressure available at the plant site (between 3 bar and 70 bar) and varying the maximum and the storage pressures. It was obtained that the configuration that assures the lowest total specific consumption is the one with 70 bars of supply pressure, but it must be considered that the related layout involves more components and complexity. The best storage pressure has proven to be 15 bar for all the supply pressure levels. Then, the second level of the procedure allows to determine the engineering design of the plant, including the specifics of the various components (compressors, inter/after-cooler and other heat exchangers), starting from the layout and parameters optimized in the previous procedure level. Finally, at the third level, the off-design analysis is carried out, allowing to evaluate the produced LNG and the plant operation conditions depending on the electric power input. The mathematical model for the engineering design and for the off-design evaluation of compressors is based on a semi-empirical approach, integrating physical models and polynomial correlations. As it regards the heat exchangers, instead, the corresponding performance are evaluated by the $\varepsilon$-NTU method in design conditions and by its modification for off-design operation.

The approach is therefore applied to a specific case study, regarding the project in Ravenna (Italy) of installing a plug \& play natural gas liquefaction plant at the port dock, for producing the demand for fuel of a ferry that works continuously in the port canal. In this application, a wind plant is chosen to provide the required electricity for the LNG process. The aim of this last section was to prove the effectiveness of the off-design model for assessing the optimal liquefaction process layout and working conditions and the wind generator size, starting from the production of LNG required by the ferry operation. In any case, the developed procedure is general and can be extended to similar case studies, 
in which an integration between a non-programmable renewable generator and a LNG production plant occurs.

Author Contributions: Formal analysis, F.C.; Methodology, M.A.A.; Software, F.M.; Supervision, M.B. and A.P.; Writing-original draft, S.O.; Writing—review \& editing, L.B. and A.D.P. All authors have read and agreed to the published version of the manuscript.

Funding: This research was funded by the Emilia Romagna Region, in collaboration with the University of Bologna (Italy) under the POR-FESR 2014-2020 financing - Clean Port project.

Conflicts of Interest: The authors declare no conflict of interest.

\section{Nomenclature}

\begin{tabular}{|c|c|}
\hline \multicolumn{2}{|c|}{ Symbols } \\
\hline$c_{p}$ & specific heat in an isobaric process $[\mathrm{kJ} / \mathrm{kg} \cdot \mathrm{K}]$ \\
\hline$\dot{C}$ & heat capacity $[\mathrm{kW} / \mathrm{K}]$ \\
\hline$e$ & total specific electric energy consumption $\left[\mathrm{kJ} / \mathrm{kg}_{\mathrm{LNG}}\right]$ \\
\hline EER & energy efficiency ratio $[-]$ \\
\hline $\mathrm{h}$ & enthalpy $[\mathrm{kJ} / \mathrm{kg}]$ \\
\hline$\dot{m}$ & mass flow rate $[\mathrm{kg} / \mathrm{s}]$ \\
\hline $\mathrm{N}$ & compressor speed [rpm] \\
\hline $\mathrm{p}$ & pressure $[\mathrm{bar}]$ \\
\hline $\mathrm{P}$ & electric power $[\mathrm{kW}]$ \\
\hline$\dot{Q}$ & thermal power $[\mathrm{kW}]$ \\
\hline$S$ & surface $\left[\mathrm{m}^{2}\right]$ \\
\hline $\mathrm{T}$ & temperature $\left[{ }^{\circ} \mathrm{C}\right]$ or $[\mathrm{K}]$ \\
\hline $\mathrm{U}$ & global heat exchange coefficient $\left[\mathrm{kW} / \mathrm{m}^{2} \mathrm{~K}\right]$ \\
\hline$v$ & specific volume $\left[\mathrm{m}^{3} / \mathrm{kg}\right]$ \\
\hline$V_{\text {disp }}$ & compressor displacement $\left[\mathrm{m}^{3}\right]$ \\
\hline$\dot{V}$ & volumetric flow rate $\left[\mathrm{m}^{3} / \mathrm{s}\right]$ \\
\hline $\mathrm{W}$ & shaft power $[\mathrm{kW}]$ \\
\hline $\mathrm{x}$ & quality $[-]$ \\
\hline \multicolumn{2}{|c|}{ Greek Symbols } \\
\hline$\Delta$ & difference $[-]$ \\
\hline$\varepsilon$ & heat exchanger effectiveness [-] \\
\hline$\eta$ & efficiency $[-]$ \\
\hline$\rho$ & density $\left[\mathrm{kg} / \mathrm{m}^{3}\right]$ \\
\hline \multicolumn{2}{|c|}{ Subscripts and Superscripts } \\
\hline$a m b$ & ambient \\
\hline$c$ & cold \\
\hline des & design \\
\hline dis & discharge \\
\hline el & electric \\
\hline em & electro-mechanical \\
\hline $\mathrm{ft}$ & flash tank \\
\hline$h$ & hot \\
\hline is & isentropic \\
\hline $\max$ & maximum \\
\hline $\min$ & minimum \\
\hline pol & polytropic \\
\hline stor & storage \\
\hline suc & suction \\
\hline sup & supply \\
\hline tot & total \\
\hline $\mathrm{v}$ & volumetric \\
\hline vap & vapour \\
\hline
\end{tabular}




$\begin{array}{ll}\text { Acronyms } & \\ \text { C1 } & \text { primary compression line } \\ \text { C2 } & \text { secondary compression line } \\ \text { HE } & \text { Heat Exchanger } \\ \text { HPN } & \text { High Pressure Network } \\ \text { JT } & \text { Joule-Thomson } \\ \text { LNG } & \text { Liquefied Natural Gas } \\ \text { LPN } & \text { Low Pressure Network } \\ \text { MHPN } & \text { Medium High Pressure Network } \\ \text { MLPN } & \text { Medium Low Pressure Network } \\ \text { NG } & \text { Natural Gas } \\ \text { NTU } & \text { Number Of Transfer Units } \\ \text { TE } & \text { Turbo Expander } \\ \text { VBA } & \text { Visual Basic for Application }\end{array}$

\section{Appendix A}

Table A1. Off-design calculation model parameters for a dataset of variable speed reciprocating compressor.

\begin{tabular}{rcc}
\hline Parameter & Value & Units \\
\hline $\mathrm{b}_{1}$ & 0.779 & {$[-]$} \\
$\mathrm{b}_{2}$ & -0.036 & {$[-]$} \\
$\mathrm{dp}$ & 0.000 & {$[-]$} \\
$\mathrm{a}_{1}$ & 1.140 & {$[-]$} \\
$\mathrm{a}_{2}$ & 0.295 & {$[-]$} \\
$\mathrm{a}_{3}$ & 447.050 & {$[\mathrm{kPa}]$} \\
$\mathrm{c}_{1}$ & 293.487 & {$[\mathrm{~K}]$} \\
$\mathrm{c}_{2}$ & 34.940 & {$[\mathrm{~K}]$} \\
$\mathrm{c}_{3}$ & $-24,202.367$ & {$[\mathrm{~K} \cdot \mathrm{kPa}]$} \\
$\mathrm{US}_{\mathrm{shel}}$ & 2.786 & {$[\mathrm{~W} / \mathrm{K}]$} \\
$\mathrm{d}_{1}$ & 1.223 & {$[-]$} \\
$\mathrm{d}_{2}$ & -0.206 & {$[-]$} \\
$\mathrm{d}_{3}$ & -0.017 & {$[-]$} \\
$\mathrm{e}_{1}$ & 0.507 & {$[-]$} \\
$\mathrm{e}_{2}$ & 0.606 & {$[-]$} \\
$\mathrm{e}_{3}$ & -0.113 & {$[-]$} \\
\hline
\end{tabular}

In the following of this Appendix A, as an example of the application of the proposed calculation model to the presented case study of Section 4, the design evaluation of the first compressor (C1-1 in Figure $2 \mathrm{~d}$ ) is presented in detail with reference to Equations (3)-(8).

Considering a design mass flow rate and a density of the fluid at the inlet of each compressor respectively equal to $0.031 \mathrm{~kg} / \mathrm{s}$ (necessary to produce $0.013 \mathrm{~kg} / \mathrm{s}$ of LNG) and to $2.175 \mathrm{~kg} / \mathrm{m}^{3}$ (fluid density at $3 \mathrm{bar}$ and $-5^{\circ} \mathrm{C}$ ), the suction volumetric flow rate is:

$$
\dot{V}_{\text {suc, }, \text { es }}=\frac{0.031}{2.175}=0.0143 \mathrm{~m}^{3} / \mathrm{s}
$$

Furthermore, the volumetric efficiency $\left(\eta_{V, \text { des }}\right)$ can be calculated as:

$$
\eta_{V, \text { des }}=0.779-0.036\left[\left(\frac{24.5}{3}\right)^{\frac{1}{1.4}}\right]=0.618
$$

being $p_{\text {dis }}=24.5$ bar and $p_{\text {suc }}=3$ bar as a result of the application of the thermodynamic optimization analysis presented in Section 2. Furthermore, a value of the isentropic coefficient equal to $k=1.4$ has been set.

As it relates the compressor speed, the compressor of the analyzed case study is characterized by a value equal to $1500 \mathrm{rpm}$, corresponding to $N_{d e s}=25 \mathrm{~Hz}$. As a consequence the displacement results equal to:

$$
V_{\text {disp }}=\frac{0.0143}{25 \cdot 0.618}=926 \mathrm{~cm}^{3}
$$


Thus, the compressor shaft power $\left(W_{\text {des }},[\mathrm{kW}]\right)$ can be calculated as:

$$
W_{\text {des }}=\frac{1}{0.98} \cdot 300 \cdot 0.0143 \cdot 1.140\left[\left(\frac{2450}{300}\right)^{0.295+\frac{1.4-1}{1.4}}+\frac{447.050}{2450}\right]=17.81 \mathrm{~kW}
$$

Once evaluated the compressor shaft power, the isentropic efficiency $\left(\eta_{i s, d e s}\right)$ can be evaluated:

$$
\eta_{i s, d e s}=\frac{0.0143 \cdot(1213-842)}{17.81} \cdot 2.175=0.643
$$

where $h_{i s}=1213 \mathrm{~kJ} / \mathrm{kg}$ and $h_{\text {suc }}=842 \mathrm{~kJ} / \mathrm{kg}$ are known from the previously presented thermodynamic analysis.

\section{References}

1. International Energy Agency: 2017. World Energy Outlook; IEA: Paris, France, 2017; Available online: https://www.iea.org/reports/world-energy-outlook-2017.

2. European Environment Agency. Greenhouse Gas Emissions from Transport: 2017; European Environment Agency: Copenhagen, Denmark, 2017; Available online: https://www.eea.europa.eu/data-and-maps/ indicators/transport-emissions-of-greenhouse-gases/transport-emissions-of-greenhouse-gases-12.

3. Schrooten, L.; De Vlieger, I.; Int Panis, L.; Chiffi, C.; Pastori, E. Emissions of maritime transport: A European reference system. Sci. Total Environ. 2009, 408, 318-323. [CrossRef] [PubMed]

4. Georgieva, E.; Canepa, E.; Builtjes, P. Harbours and air quality. Atmos. Environ. 2007, 41, 6319-6321. [CrossRef]

5. Chevron. Diesel Fuel Technical Review; Chevron: San Ramon, CA, USA, 2007; Available online: www.chevron. com/products/prodserv/fuels/bulletin/diesel.

6. International Maritime Organization (IMO). Available online: http://www.imo.org/en/OurWork/Environment/ PollutionPrevention/AirPollution/Pages/Sulphur-oxides-(SOx)\%E2\%80\%93-Regulation-14.aspx (accessed on 5 November 2019).

7. Kumar, S.; Kwon, H.-T.; Choi, K.-H.; Cho, J.H.; Lim, W.; Moon, I. Current status and future projections of LNG demand and supplies: A global prospective. Energy Policy 2011, 39, 4097-4104. [CrossRef]

8. Burel, F.; Taccani, R.; Zuliani, N. Improving sustainability of maritime transport through utilization of Liquefied Natural Gas (LNG) for propulsion. Energy 2013, 57, 412-420. [CrossRef]

9. Taljegard, M.; Brynolf, S.; Grahn, M.; Andersson, K.; Johnson, H. Cost-Effective Choices of Marine Fuels in a Carbon-Constrained World: Results from a Global Energy Model. Environ. Sci. Technol. 2014, 48, 12986-12993. [CrossRef] [PubMed]

10. Livanos, G.A.; Theotokatos, G.; Pagonis, D.-N. Techno-economic investigation of alternative propulsion plants for Ferries and RoRo ships. Energy Convers. Manag. 2014, 79, 640-651. [CrossRef]

11. Martin, P.-Y.; Fischer, B. Natural Gas Liquefaction Processes Comparison. In Proceedings of the 14th International Conference and Exhibition on Liquefied Natural Gas (LNG-14), Doha, Qatar, 21-24 March 2004.

12. Bosma, P.; Nagelvoort, R.K. Liquefaction Technology; Developments through History. In Proceedings of the 1st Annual Gas Processing Symposium, Doha, Qatar, 10-12 January 2009.

13. Van de Graaf, J.M.; Pek, B. Large-Capacity LNG Trains-The Shell Parallel Mixed Refrigerant Process. Business Briefing, 28 October 2005.

14. Berger, E.; Forg, W.; Heiersted, R.S.; Paurola, P. The MFC ${ }^{\circledR}$ (Mixed Fluid Cascade) Process for the First European Baseload LNG Production Plant. Linde, 13 July 2003.

15. Waldmann, I.B. Evaluation of Process Systems for Floating LNG Production Units. In Proceedings of the Tekna Conference, Stavanger, Norway, 18-19 June 2008.

16. Foglietta, J.H. Production of LNG using Dual Independent Expander Refrigeration Cycles. In Proceedings of the AIChE Spring National Meeting, New Orleans, LA, USA, 10-14 March 2002.

17. Ancona, M.A.; Bianchi, M.; Branchini, L.; De Pascale, A.; Melino, F.; Scarponi, L.B.; Mormile, M.; Palella, M. Investigation on Small-scale Low Pressure LNG Production Process. Appl. Energy 2018, 227, 672-685. [CrossRef]

18. Lim, W.; Choi, K.; Moon, I. Current Status and Perspectives of Liquefied Natural Gas (LNG) Plant Design. Ind. Eng. Chem. Res. 2013, 52, 3065-3088. [CrossRef] 
19. He, T.; Karimi, I.A.; Ju, Y. Review on the design and optimization of natural gas liquefaction processes for onshore and offshore applications. Chem. Eng. Res. Des. 2018, 132, 89-114. [CrossRef]

20. He, T.; Liu, Z.; Ju, Y.; Parvez, A.M. A comprehensive optimization and comparison of modified single mixed refrigerant and parallel nitrogen expansion liquefaction process for small-scale mobile LNG plant. Energy 2019, 167, 1-12. [CrossRef]

21. Kohler, T.; Bruentrup, M.; Key, R.D.; Edvardsson, T. Choose the best refrigeration technology for small-scale LNG production. Hydrocarb. Process 2014, 1, 45-52.

22. Kim, J.; Seo, Y.; Chang, D. Economic evaluation of a new small-scale LNG supply chain using liquid nitrogen for natural-gas liquefaction. Appl. Energy 2016, 182, 154-163. [CrossRef]

23. Ancona, M.A.; Bianchi, M.; Branchini, L.; De Pascale, A.; Melino, F.; Mormile, M.; Palella, M. On-Site LNG Production at Filling Stations. Appl. Therm. Eng. 2018, 137, 142-153. [CrossRef]

24. Ancona, M.A.; Bianchi, M.; Branchini, L.; De Pascale, A.; Melino, F.; Mormile, M.; Palella, M. A Novel Small Scale Liquefied Natural Gas Production Process at Filling Stations: Thermodynamic Analysis and Parametric Investigation. In Proceedings of the ASME Turbo Expo 2016, Seoul, Korea, 13-17 June 2016.

25. Available online: http://www.snamretegas.it/it/business-servizi/Archivio/Anno-termico_2015_2016/Info-agliutenti/1_rete-naz-gasd.html (accessed on 5 November 2019).

26. He, T.; Ju, Y. Optimal synthesis of expansion liquefaction cycle for distributed-scale LNG (liquefied natural gas) plant. Energy 2015, 88, 268-280. [CrossRef]

27. Remeljej, C.W.; Hoadley, A.F.A. An exergy analysis of small-scale liquefied natural gas (LNG) liquefaction processes. Energy 2006, 31, 2005-2019. [CrossRef]

28. Li, W. Simplified steady-state modeling for variable speed compressor. Appl. Therm. Eng. 2013, 50, 318-326. [CrossRef]

29. Bianchi, M.; Branchini, L.; De Pascale, A.; Melino, F.; Ottaviano, S.; Peretto, A.; Torricelli, N. Performance prediction of a reciprocating piston expander with semi-empirical models. In Proceedings of the 10th International Conference on Applied Energy (ICAE2018), Hong Kong, China, 22-25 August 2018.

30. Darr, J.H. Modeling of an Automotive Air Conditioning Compressor Based on Experimental Data. Ph.D. Thesis, Air Conditioning and Refrigeration Center, College of Engineering, University of Illinois at Urbana-Champaign, Urbana, IL, USA, February 1992.

31. Ancona, M.A.; Bianchi, M.; Branchini, L.; Brilloni, A.; Catena, F.; De Pascale, A.; Melino, F.; Peretto, A.; Liverani, A.; Palella, M. Parametric Analysis on Small Scale System for Liquefied Natural Gas production. In Proceedings of the 13th Conference on Sustainable Development of Energy, Water and Environment Systems, Palermo, Italy, 30 September-4 October 2018.

32. Available online: https://www.terna.it/it-it/sistemaelettrico/statisticheeprevisioni/datistatistici.aspx (accessed on 5 November 2019).

(C) 2020 by the authors. Licensee MDPI, Basel, Switzerland. This article is an open access article distributed under the terms and conditions of the Creative Commons Attribution (CC BY) license (http://creativecommons.org/licenses/by/4.0/). 